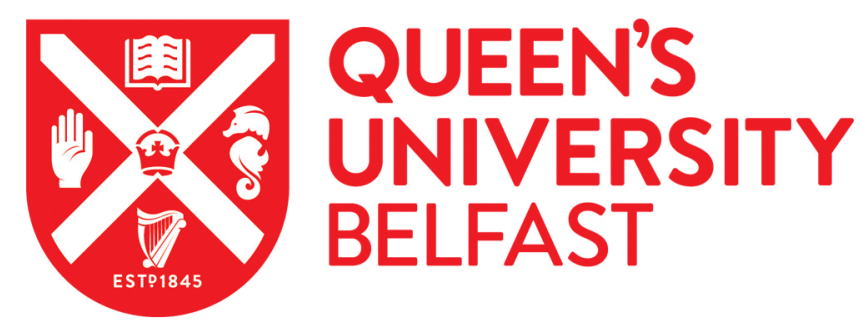

\title{
How much risk ought we to take? Exploring the possibilities of risk- sensitive consequentialism in the context of climate engineering
}

Stelzer, H., \& Schuppert, F. (2016). How much risk ought we to take? Exploring the possibilities of risk-sensitive consequentialism in the context of climate engineering. Environmental Values, 25(1), 69-90.

https://doi.org/10.3197/096327115X14497392134928

Published in:

Environmental Values

Document Version:

Peer reviewed version

Queen's University Belfast - Research Portal:

Link to publication record in Queen's University Belfast Research Portal

Publisher rights

Copyright 2016 Environmental Values

\section{General rights}

Copyright for the publications made accessible via the Queen's University Belfast Research Portal is retained by the author(s) and / or other copyright owners and it is a condition of accessing these publications that users recognise and abide by the legal requirements associated with these rights.

Take down policy

The Research Portal is Queen's institutional repository that provides access to Queen's research output. Every effort has been made to ensure that content in the Research Portal does not infringe any person's rights, or applicable UK laws. If you discover content in the Research Portal that you believe breaches copyright or violates any law, please contact openaccess@qub.ac.uk. 


\title{
How much risk ought we to take? Exploring the possibilities of risk-sensitive consequentialism in the context of climate engineering
}

\begin{abstract}
:
When it comes to assessing the deontic status of acts and policies in the context of risk and uncertainty moral theories are often at a loss. In this paper we hope to show that employing a multi-dimensional consequentialist framework provides ethical guidance for decision-making in complex situations. The paper starts by briefly rehearsing consequentialist responses to the issue of risk as well as their shortcomings. We then go on to present our own proposal based on three dimensions: well-being, fairness and probability. In the last section we apply our approach to a comparison of different climate policy options, including stratospheric solar radiation management.
\end{abstract}

Keywords:

Climate engineering - consequentialism - risk - fairness - climate policy

\section{Introduction}

As more and more time elapses without radical mitigation efforts on a global level, discussions on the ethical, technological and political viability of planetary scale climate engineering (CE) deployment intensify. Within these debates on CE it is striking to observe that very little is said about the merits of employing a consequentialist framework for assessing the ethical and moral status of different CE proposals. In fact, it seems as if consequentialism either is only used within climate economics, that is in the form of rather standard cases of cost-benefit-analysis and cost-effectiveness analysis, or consequentialism is criticised for being ill-equipped to deal with situations in which the consequences of our 
actions are laden with risks and uncertainties (Norcross, 1999; Lenman, 2000). While it is true that factors such as risk and uncertainty present a major challenge for correctly assessing the deontic status of actions, it is highly questionable whether consequentialism as such should be dismissed on these grounds, especially since outside of practical philosophy consequentialist reasoning plays an important role.

In this paper we set out to explore the possibility of a risk-sensitive multi-dimensional consequentialism, which is able to provide ethical guidance for our decision-making in complex situations such as rapid climate change. While there exist certain irreducible issues when it comes to assessing the deontic status of acts and policies in the context of uncertainty, we hope to show that employing a multi-dimensional consequentialist framework offers very plausible and situation-sensitive answers.

The paper starts by briefly rehearsing consequentialist responses to the issue of risk. We focus on so-called expected well-being approaches and Martin Peterson's (2012; 2013) argument for a multi-dimensional consequentialist framework, which seems particularly suitable for dealing with complex decision-making situations and cases of risk. As we will argue, while traditional expected well-being consequentialism is too mono-dimensional, Peterson's account - despite its initial appeal - has some problematic features of its own. We then go on to present our own proposal which argues that consequentialists should: i) be value-pluralist and multi-dimensional in their axiology; ii) avoid probability-domination; iii) define guardrails and thresholds for permissible outcomes; and iv) focus on the overall satisfaction of a range of relevant thresholds (including probability) within a satisficing consequentialist framework. In the last section of the paper, we will apply our theory to a hypothetical decision on (not) employing stratospheric solar radiation management (S-SRM) and briefly sketch the prospects and limits of our consequentialist framework. 


\section{Consequentialism and Risk}

In its simplest form consequentialism can be characterized as the doctrine that the deontic status of an act (including omissions, sets of acts and courses of action) depends only on consequences. While there exist many different forms of consequentialism with regard to the class of actions which fall under the doctrine and the range of right- and wrong-making properties, the key-aspect for consequentialists dealing with risk and uncertainty lies in defining the kind of consequences on the basis of which the deontic status of an act is judged. ${ }^{1}$ Traditionally, most consequentialists subscribe to one of two camps: either they are actualists or they are probabilists.

Actualists hold that only actual consequences matter. If an act is wrong depends solely on the actual consequences of that act (and often on the consequences that would have materialized if a different action had been taken). According to this view hard-nosed actualist act-consequentialists might hold that pointing a half-loaded gun to the head of a friend and pulling the trigger is not morally wrong as long as no bullet is discharged and the friend is not harmed. There are of course many other reasons for which such an action might be considered blameworthy (e.g. Thomson 1986; Oberdiek 2012) but speaking strictly in terms of actual consequences, no moral wrong was committed. ${ }^{2}$ What matters for our discussion here is that actualists avoid the issue of risk imposition and risk taking by focusing exclusively on actual outcomes/consequences. In cases of long-term risks, then, actualists can only assess the deontic status of a certain act, or policy, ex post in the distant future. In many cases the fact that actualists are only able to pass judgment ex post is of little concern, since the relevant consequences materialize directly after or very shortly after the act. In the case of climate engineering though it might take decades before we know whether an intervention

\footnotetext{
${ }^{1}$ For an overview of consequentialism and its different battlegrounds see Sinnott-Armstrong (2012), Darwall (2003), and Smart and Williams (1973).

2 Actually not all actualist consequentialists would agree with this assessment, since actualist ruleconsequentialists might argue that general careless (or risky) behaviour does actually lead to overall negative consequences.
} 
like S-SRM actually works, or whether it wracks havoc. This raises the obvious issue of determining at which point in time $t$ we could/should/ought to assess the relevant consequences for defining the deontic status of an act, an issue which is not only of importance for actualists.

Probabilists meanwhile hold that probable consequences matter. Probabilists come in many shapes and forms but the most relevant for our discussion here are those which hold that (subjectively or objectively) expected consequences matter. ${ }^{3}$ The standard case for this variant of probabilism is expected well-being maximization (e.g. Smart 1973; Jackson 1991). ${ }^{4}$ Probabilist consequentialists of the expected well-being variety carefully weigh the possible outcomes of an act, that is, an act's best and worst possible outcomes, and factor in the probability for each outcome. Thus, expected well-being consequentialists would regularly choose an act which produces relatively good outcomes with a high probability over acts which either produce very good or very bad outcomes with low probability for the very good outcome. Probabilist consequentialists thus are able to easily differentiate between risky acts with potentially catastrophic outcomes and relatively safe bets.

However, as Peterson (2013: 104 \& 107) points out, probabilist expected well-being consequentialists tend to discount optimal outcomes due to their mono-dimensional value ordering which is virtually probability dominated, since they focus on the most likely outcome(s) only. That is to say, for expected well-being consequentialists it turns out that in many cases it is first and foremost probability which influences the deontic status of a given act. While being mono-dimensionally probability dominated might be considered unobjectionable in cases in which probabilities are with virtual certainty objectively defined, being probability dominated seems rather problematic in cases in which probabilities are less

\footnotetext{
3 Whether one specifies expected consequences on the basis of subjective or objective probabilities can obviously make a large difference in practice. However, for our discussion here this is a point we can leave aside for now.

${ }^{4}$ In this paper we will ultimately defend a satisficing account of consequentialism. However, for our discussion here we go with the standard probabilist view, i.e. expected well-being maximization.
} 
reliable. For expected well-being consequentialists there does not seem to exist a difference in weight between probabilities based on standard procedures (e.g. the flip of a coin) and multi-variable calculations with significant error margins (e.g. predictions for the effects of large-scale geoengineering efforts). Part of this problem seems to stem from taking expected well-being and probabilities as compatible features of a mono-dimensional ordering system.

In response to these issues Peterson $(2012 ; 2013)$ presents his account of a multidimensional consequentialism. Peterson argues that his account offers advantages over both mono-dimensional actualism and well-being consequentialism because of the introduction of three separate moral dimensions: individual well-being, equality and risk. Peterson (2013: 105-9) holds that these three dimensions are irreducible and incommensurable, which means that they cannot be collapsed into a single scale.

Furthermore Peterson (2013: ch. 2) argues for accepting a distinctly non-binary conception of moral rightness. In other words, acts are not either right or wrong but that their rightness/wrongness comes in degrees. ${ }^{5}$ While we very much agree with the basic tenet of Peterson's multi-dimensional consequentialism, that is, its commitment to three irreducible moral dimensions, and while we agree at least in part with the ideas of incomparability and degrees of moral rightness, at closer inspection we disagree with Peterson's account on two important scores: first, Peterson's actualist theory values optimal outcomes above everything else, which means that it is maximization dominated; second, Peterson's theory gives us a particular understanding of incomparable sets of degrees of rightness, which in conjunction with the adoption of weighted randomization as a decision-making procedure, renders Peterson's theory less informative and action-guiding than it could be. While our main disagreement with Peterson's multi-dimensional consequentialism is with regard to the first

\footnotetext{
${ }^{5}$ An exception to this rule might be when we have an option on the table which is pareto optimal with respect to all dimensions (i.e. the option scores best in comparison with the other available options in all three dimensions). In this case we may call this option simply right.
} 
point (i.e. maximization domination), as our hypothetical case-study will hopefully show the disagreement over the latter point is also of significance. Let us briefly explain both points.

First, Peterson's theory offers implausible answers in cases like Jackson's (1991: 4623) example of the treatment dilemma: ${ }^{6}$

A doctor must decide on the correct treatment for a patient who has a serious skin complaint. Careful consideration of the literature has led her to the following options. B will relieve the condition but will not completely cure it. One of A and C will completely cure the skin condition; the other will kill the patient, but there is no way she can tell which of the two is the perfect cure and which is the killer.

While Jackson argues for option B on probabilist grounds, according to Peterson, as consequentialists we should preserve the actualist's focus on best possible outcomes, which means that in the case described above treating the patient with B must always be considered wrong, since no matter whether $\mathrm{A}$ or $\mathrm{C}$ is the right cure, only $\mathrm{A}$ or $\mathrm{C}$ can deliver the optimal outcome. Hence Peterson argues that A and C should both be considered right to a degree and wrong to a degree, while B should be simply dismissed. This assessment, however, seems both counterintuitive and misguided, since it would ask of policy-makers to play Russian roulette rather than to choose a reasonably safe (even though not perfect) option. A moral philosopher might have the luxury of assessing the situation ex post and proclaim that killing the patient was wrong, but that does not help the patient, who was killed rather than relieved of a medical condition in lack of a better and safer cure. Therefore, Peterson's multidimensional consequentialism simply seems unable to deal with scenarios that are both haunted by uncertainty and very risky. As we will argue below, adopting a multi-dimensional

\footnotetext{
${ }^{6}$ Interestingly enough, Peterson (2013: 106-7) uses this example to defend his view. However, we think his interpretation is misguided due to his theory's maximization domination.
} 
expected well-being approach in conjunction with threshold levels for establishing moral permissibility could avoid the counterintuitive outcome discussed above.

Second, even if we leave extreme cases like the treatment dilemma aside and focus on situations in which we simply have a range of options which score differently with respect to well-being, equality and risk, Peterson's account might leave us unsatisfied. As we said at the beginning of this paper, we want to explore the possibility of presenting a risk-sensitive consequentialism which can also provide at least some ethical guidance for decision-makers. This is not to say that our account will be able, or should be able, to say for every situation S what the morally right course of action is. Instead we want our theory to define a range of theoretically (im)permissible options and a matrix which allows decision-makers to see how different options can produce different outcomes across three irreducible moral dimensions. This is exactly where Peterson's theory partially struggles. Peterson is committed to both a particular understanding of the irreducibility and incomparability of the three moral dimensions, and a particular conception of degrees of moral rightness, which means in most complex cases we will end up with statements of the following kind:

Option A is $20 \%$ right with regard to well-being, 30\% right with regard to equality and $50 \%$ right with regard to risk. Option B meanwhile is $30 \%$ right with regard to wellbeing, $50 \%$ right with regard to equality and $20 \%$ right with regard to risk, while option C is $50 \%$ right with regard to well-being, $20 \%$ right with regard to equality and $30 \%$ right with regard to risk. Peterson suggests that taking these degrees of rightness into account we should adopt a weighted lottery as the appropriate decision-making tool.

The problem with statements like this and the proposed decision-making procedure is that they give very little ethical guidance to decision-makers. In fact, if we followed Peterson's proposal no real decision would need to be made as the actual decision is the outcome of a weighted lottery. Once we have agreed on the values in the matrix, we just 
perform a weighted lottery and go with whatever the result is. While we should of course consider each and every option which might be the right one (which is exactly what the weighted lottery is designed to do), this does not exempt us from the responsibility to argue for or against a certain option including on the basis of cross-dimensional considerations. Even though the different moral dimensions do not collapse into a single one and are strictly speaking non-comparable, we can have weighty reasons to prefer - for example - well-being to equality or to take higher risks in certain situations. The incomparability of the dimensions in a strict sense does not necessarily lead to a position that prohibits trade-offs between different dimensions based on moral and other reasons. Peterson's account seems to exclude carefully deliberation over the different options on the table and other reasons we might have for preferring A over B. Instead, all possible considerations are expected to have been in the matrix, which means Peterson's account assumes that the incomparability of the three separate moral dimensions is absolute, not only with regard to moral rightness (which is a claim we agree with) but also with regard to the decision-making, that is, it prevents us from using other reasons for making a decision or for taking a particular option of the table (for instance because it violates an absolute threshold).

To be clear, Peterson does not claim that any multi-dimensional consequentialism must subscribe to either absolute incomparability or weighted randomization as decisionmaking procedure. Therefore, our disagreement with Peterson's theory is internal and with regard to negotiable ${ }^{7}$ features of his multi-dimensional consequentialism, that is, it is with regard to how one should properly conceptualise a multi-dimensional consequentialism, not whether such an account is at all tenable. As Peterson (2013) himself points out, embracing his particular understanding of moral degrees and his proposed decision making procedure is in a sense optional and independent of the deeper commitment to multi-dimensional

\footnotetext{
${ }^{7}$ By calling these features 'negotiable' we want to highlight the fact that the most radical and important aspect of Peterson's multi-dimensional consequentialism, namely, its commitment to three irreducible and morally incomparable moral dimensions remains in our proposal intact.
} 
consequentialism as such. ${ }^{8}$ While Peterson's multi-dimensional consequentialism is certainly risk-sensitive, we want to argue that adopting a satisficing expected well-being account allows us to establish clearer boundaries of moral permissibility, that it avoids the problems associated with Peterson's actualist account, and that it lends itself to adopting different decision-making procedures.

\section{Sufficiency-restrained multi-dimensional consequentialism}

From what we said so far we can already gather a long list of requirements which we want our alternative conception of consequentialism to fulfil. First, it should be risk-sensitive. Second, it should neither be dominated by probability, nor by maximization. Third, our consequentialist framework should provide ethical guidance for practical decision-making. Admittedly, this is a rather tall order.

Based on our considerations in part one, we want to stick to the idea of a multidimensional consequentialism. Like Peterson we will define three basic moral dimensions: individual well-being, probability and fairness.

Well-being matters because it tells us how people get affected and which gains or losses an outcome will bring about. Just like Peterson (2013: 50), we take the dimension of well-being to be concerned with every individual's well-being, so as to respect the separateness of persons. This is an important point, since most standard consequentialist views see individuals only as substitutable containers of well-being, which is actually one of the reasons why critics of satisficing consequentialism such as Tim Mulgan (2001) assume that satisficers can get away with murder, a conclusion that is simply wrong if one's wellbeing dimension respects the separateness of persons. ${ }^{9}$

\footnotetext{
${ }^{8}$ We are grateful to an anonymous reviewer to encourage us to clarify this point.

${ }^{9}$ We will return to the issue of satisficing and Mulgan's criticism thereof below.
} 
In terms of well-being we focus on whether an option enables or disables the realization of a person's fundamental interests. ${ }^{10}$ The fulfilment of those interests establishes a threshold of well-being. Framing well-being in this way means that one should consider options which would lead to people falling below such a threshold (so that they are unable to satisfy their fundamental interests) morally impermissible, as far as such consequences are predictable and could easily be avoided by some other course of action. With this interestbased approach we distance ourselves from the problematic utility assumption underlying many consequentialist positions in economic theory as well as their attribution of monetary values to all benefits and burdens, including human life, physical security, subsistence and health.

The protection of people's fundamental interests might be considered a rather uncontroversial minimum standard. Whether such a threshold is demanding enough, considering that in complex situations (in which no easily available pareto-optimal option exists) mere basic interest fulfilment would be considered good enough (from the viewpoint of moral permissibility), is a question which certainly might cause some controversy. Moreover, in many complex decision scenarios it is unlikely that any option will be able to guarantee that no person's basic rights are violated, hence it is important to allow for some leeway. Furthermore, in most realistic scenarios, we will only have a rough idea about what kind of consequences might materialize if we choose a particular option. Due to issues of complexity and uncertainty, we will only be able to sketch likely outcome scenarios. These scenarios can be described as consequence-bundles understood as groups of possible consequences according to certain features (i.e. catastrophic ones and fairly positive ones). Depending on the uncertainty and complexity of the choice situation, these consequence-

\footnotetext{
${ }^{10}$ Fundamental interests refer to the moral interests people have for leading a decent life/ good life (depending on the account of fundamental interests one subscribes to). Fundamental interests ground basic rights to the things and goods people need for leading a decent life / good life. For an account of fundamental interests see Schuppert (2013).
} 
bundles can be more or less spread-out and wide. Positive well-being gains in such bundles could be construed as chances, while well-being losses could be understood as risks. What we have to do then is to use our best available predictive tools in order to sketch what chances and risks a certain option might offer.

Probability matters because it tells us how good or bad our chances are that a certain consequence, or in most cases bundle of consequences, materialises and how large the uncertainties are we are facing. Take the case of having in a situation $\mathrm{s}$ two options $\mathrm{O}_{1}$ and $\mathrm{O}_{2}$. $\mathrm{O}_{1}$ brings about consequence bundle $\mathrm{A}$ or bundle $\mathrm{B}$, with $\mathrm{A}$ meeting our well-being threshold, while B fails to satisfy our well-being threshold. $\mathrm{O}_{2}$, meanwhile, will either result in consequence bundle $\mathrm{C}$ or bundle $\mathrm{D}$, with $\mathrm{C}$ vastly exceeding our well-being threshold (thus promising great well-being gains), while D fails to satisfy our well-being threshold. If we were not to take probabilities into account, $\mathrm{O}_{2}$ would be clearly more attractive than $\mathrm{O}_{1}$. However, once one takes probabilities into account this might well change, for instance if the probability distribution for $\mathrm{O}_{1}$ was $(0.5 \mid 0.5)$ and for $\mathrm{O}_{2}(0.02 \mid 0.98)$. Now the potential wellbeing gains of choosing option $\mathrm{O}_{2}$ seem vastly less attractive, since the probability of bundle C coming about is only 0.02 .

It is important to be clear what the probability dimension refers to: technological feasibility, political and economic feasibility, or the probability of attaining a particular outcome/consequence bundle within a chosen option. In our view, the probability dimension can only be concerned with the latter and not with the former. Which options $\mathrm{O}_{1} \ldots \mathrm{O}_{\mathrm{n}}$ are at all on the table, which is an issue of political and economic feasibility, is another question. In fact, this is an issue which has to be dealt with prior to deciding which option one ought to choose, since the description of each and every option (and indirectly thus of every consequence bundle) is based on a range of political and economic feasibility assumptions. Once we know which options are on the table, we need to compare the available options with 
regard to their performance in all three dimensions, well-being, fairness and probability. Our multidimensional framework therefore provides a second order evaluation of options based on normative criteria. However, feasibility constraints come into play again once we have done our normative assessment of all available options; after all, it might well be the case that the normatively speaking best option proves utterly unfeasible because of political and economic circumstances.

Our basic starting point for factoring risk into our framework is therefore the assessment of every considered option's possible consequence bundles and how they perform with regard to the relevant thresholds. However, in contrast to the example given above in many cases we will not be able to assign numerical values to a bundle's probability and consider the full range of possible outcomes of an option; moreover, we will have to carefully defend the probabilities we assign to particular consequence bundles and make sure that we reflect existing uncertainties within our probability dimension.

Furthermore, as we saw in our (and Peterson's) discussion of expected well-being theories, if one were to apply a mono-dimensional scale in conjunction with a focus on probable (and also possible) consequences one's decision-making gets easily dominated by probabilities, that is, one tends to focus on the most likely outcome only. One way to avoid the problem of probability domination is to use a multi-dimensional framework, which does not allow for collapsing probability into one ordering scale with well-being. Employing such a multi-dimensional framework within a satisficing theory has the further advantage that one determines separate probability thresholds, since for positive consequence bundles we want probability to be high (i.e. the outcome to be likely), while for negative consequence bundles we want probability to be low (i.e the outcome to be unlikely). Establishing different thresholds allows us to exclude those options which feature consequence bundles that score very well in terms of well-being but which come with very low and unreliable probabilities 
for these positive bundles. The same goes also the other way around, which means that spelling out probability and uncertainty while establishing thresholds also allows for identifying alarmist doomsday scenario outcomes, which are so extremely unlikely that they should not over-proportionally influence our decision making. ${ }^{11}$

Even though our approach is therefore not probability dominated it is still risk sensitive, as it takes the risks of different options into account, by including the risks that we ascribe to different options in our well-being function and by mapping uncertainty in our probability function. By setting a certain threshold for well-being as well as for the probabilities of all these outcomes such an approach can be tuned to be more or less risk sensitive, and it can be done so in respect to the underlying problem situation and to what is at stake. Therefore, one of our core assumption is that the moral (im)permissibility of an option may change, when we consider it in different scenarios. Based on these consideration we assume for our multi-dimensional satisficing consequentialism, a) that we need to have probability thresholds, that neither arbitrarily ignore unlikely or unpredictable catastrophic outcomes, nor are dominated by very unlikely scenarios; ${ }^{12}$ and b) that such thresholds themselves can be variable, depending on the scenario we are dealing with and the possible alternatives available.

What matters beside the consequences and their probability is also how the costs and benefits of an option are distributed. We therefore include a third moral dimension: fairness. As Peterson points out (2013: 74) fairness is simply broader than equality since it takes considerations beyond pure equality into consideration. ${ }^{13}$ Fairness matters as it tells us

\footnotetext{
11 That is not to say that satisficing consequentialists like us must necessarily treat all doomsday scenarios as cases of unrealistic alarmism. Instead it allows us to put things into perspective, since keeping probability a separate indicator is less likely to obscure our ordering than a mono-dimensional scale. Basically, setting a risk threshold prevents us from extreme risk-aversion and extreme risk-taking.

${ }^{12}$ In order to avoid arbitrariness we obviously have to choose our probability thresholds on the basis of good, defensible reasons.

${ }^{13}$ According to Peterson both equality and fairness are suitable categories to be used. As Peterson (2013: 74) puts it, 'multi-dimensional consequentialist[s] ha[ve] some freedom of choice' with regard to this question. We
} 
whether people get equally affected, or whether some benefit at the expense of others. For the dimension of fairness we operate with the assumption that an outcome (including distributions) can only be considered fair if it does not arbitrarily disadvantage certain people, groups or generations, that is, if the distribution of benefits and burdens associated with an outcome track relevant reasons. This means that according to our criterion of fairness an act which intentionally produces well-being for one group at the expense of another group should be, in the absence of other (possibly overweighing) reasons, considered unfair.

We want to suggest in this paper to spell out the idea of fairness along the lines of a gradual scaling, spanning from very fair to very unfair (with a range of intermediate labels such as quite fair, somewhat fair, somewhat unfair, quite unfair), assuming that somewhat fair might be an acceptable threshold for most cases. In fact, based on the assumption that it is morally impermissible to gratuitously compromise the rights and interests of people regardless of their spatial and temporal placement, we suggest that the principles of wellbeing and fairness are to be applied both globally and intergenerationally. One significant advantage of this reading of well-being and fairness is the aspect that it safeguards the fundamental interests of the most vulnerable, i.e. the poor and future generations. However, as pointed out earlier, under the pressure of non-ideal circumstances, a limited range of available options might lead in certain situations to a state of affairs in which we might have to settle for a somewhat unfair option simply because no better options are at hand. This is a problem we will discuss during the application of our consequentialist framework to the issue of climate engineering.

What we advocate in this paper, then, is to settle for a three-dimensional satisficing consequentialism, which sets separate threshold levels for each moral dimension. As satisficing consequentialism is controversial let us make clear what kind of satisficing factors other than equality can inform what counts as fair in particular circumstances. 
consequentialism we advocate and why we take it to avoid the pitfalls commonly associated with satisficing.

First of all, it is important to note that we argue for satisficing consequentialism as a suitable strategy in complex decision-making situations with significant variations in both possible outcomes and assumed probabilities and in which no pareto-optimal solution (across all three irreducible moral dimensions) exists. If there exists a clearly discernible paretooptimal option across all three moral dimensions this option ought to be chosen, since it is the only morally right option. If however, no option exists that is pareto-optimal across all three dimensions, due to the dimensions' irreducibility and incomparability, no option can be labelled as being fully morally right. Instead several options might be morally permissible. ${ }^{14}$

Second, in order to establish which options ought to be considered morally permissible, we advocate satisficing in the form of threshold level setting for each moral dimension. Hence, only options which satisfy the permissibility thresholds set for each dimension are to be considered morally permissible. Using the idea of satisficing as a way of establishing moral permissibility thresholds within a multi-dimensional consequentialist framework is thus entirely different from using satisficing as a general principle within a mono-dimensional scheme of what has been labelled 'blatant moral satisficing'(Slote 1984; Mulgan 1993). Blatant moral satisficing is simply too crude, since it allows for a range of counterintuitive actions, such as making people gratuitously worse off as long as they stay above the threshold (Bradley 2006). ${ }^{15}$ Our version of satisficing avoids these issues by i) valuing the separateness of persons, ii) disaggregating the consequences of an act along three irreducible moral dimensions, and iii) establishing a non-suboptimality condition which holds that acts which are in comparison to another available option pareto-suboptimal (i.e. worse across all three dimensions) are morally impermissible. The reason for the non-suboptimality

\footnotetext{
${ }^{14}$ What will happen in cases in which no option satisfies the thresholds of all three dimensions is a question we will address below.

${ }^{15}$ Rogers (2010) presents a mono-dimensional form of satisficing consequentialism which avoids this problem.
} 
condition is simply that if we were to choose a suboptimal option we would fail to bring about the best moral outcome amongst two comparable options, which clearly runs counter to the underlying rationale of our expected outcome consequentialism, since the idea of satisficing for establishing moral permissibility only comes into play once we have no comparable options available. Thus, in the following table only options A and C are morally permissible even though B, too, satisfies all the established threshold levels. However, C is across all three dimensions better than option B, which means that B fails to satisfy the nonsuboptimality condition.

\begin{tabular}{|c|c|c|c|c|}
\hline & Well-being & Probability & Fairness & Permissibility \\
Threshold value & 5 & 2 & 2 & \\
permissibility & & & 3 & morally \\
\hline Option A & 8 & 3 & 3 & permissible \\
\hline Option B & 6 & 3 & & morally \\
& & & & mormissible \\
\hline Option C & 7 & 4 & & permissible \\
\hline
\end{tabular}

table 1

Third, if there is no option which meets all the threshold levels across the three dimensions, we face a situation of a problematic nature. Thus, we need to carefully assess the potential negative consequences for well-being involved in each option, assess the probabilities and compare the expected fairness and well-being outcomes so as to decide which option is morally permissible to choose in these non-ideal circumstances. That is, we assume here that even in dilemma situations one or more options are morally permissible. A 
different way of interpreting dilemma situations would be to say that all options are morally wrong, but some are less bad than others. We find this second reading implausible. Naturally in cases in which each option features a worst outcome which threatens to fail to satisfy all our sufficiency constraints, and if the probabilities in these cases are rather unreliable, it may be difficult to establish which option(s) should be considered morally permissible. We will come back to this problem in our example below.

What interests us in the idea of satisficing is therefore not that it is morally permissible for an agent to simply identify a 'good enough' option and to go for it. Rather, satisficing consequentialism is interesting as it includes the idea of some aspiration or sufficiency level, which can be understood as a threshold level of moral permissibility that could be reached by different options (Pettit 1984: 166). ${ }^{16}$ By combining the idea of satisficing with a multi-dimensional approach, which assumes value incommensurability and incomparability, satisficing consequentialism provides us with a great tool for carefully unpacking the complex consequences of different options. The exact decision-making procedure for choosing an option is not fixed, though it seems sensible to assume that the expected overshoot (i.e. the well-being and fairness gains above the threshold) as well as the overall probability should influence the decision. Instead of using a weighted lottery and leaving the decision up to chance, however, we propose that one of the morally permissible options is chosen on the basis of careful deliberation and possibly the consideration of other noteworthy reasons, external to the three moral dimensions discussed above. Moreover, because our account of multi-dimensional consequentialism focuses on expected outcomes which satisfy a set of particular moral permissibility thresholds it avoids Peterson's issue of maximization domination. In a nutshell, our approach therefore leads to the following decision rules:

\footnotetext{
${ }^{16}$ Where such a threshold should lie is of course open to debate and the attractiveness of our framework somewhat depends on choosing appropriate threshold levels.
} 
(1) If there is one option which not only satisfies all thresholds but which is also pareto-optimal across all three dimensions, this option ought to be chosen;

(2) If no pareto-optimal option exists, all the options which meet all the thresholds across all three dimensions are morally permissible as long as they satisfy the nonsuboptimality condition;

(3) If no option satisfies all thresholds we face a dilemma, since no option satisfies the demands of our framework.

As mentioned above, however, even in dilemma situations we hold it to be possible to assess options so as to find out which options can be considered morally permissible in these nonideal circumstances.

\section{Consequentialist Decision-Making and Climate Engineering}

As put forward in the introduction the development of our multidimensional consequentialism has been inspired by problems of climate change and the possible use of climate engineering techniques. One technique that seems of special interest to philosophers due to the difficult problems it raises for decision-making under uncertainty is stratospheric solar radiation management (S-SRM), the currently most discussed albedo modification technique. S-SRM involves increasing the amount of aerosol particles in the lower stratosphere as a means to increase the reflection of sunlight beyond what is reflected by the naturally-occurring stratospheric aerosol layer. Particles could either be injected directly, or formed via injection of precursor gases like SO2, which are then converted into particles (Schäfer et al. 2015). Due to its different features as discussed below S-SRM makes an interesting case for applying our account as developed in part two. However, this application is to be seen as a case study rather than as a targeted policy advice. Our main concern here is 
to bring forward some merits and problems of our approach, also indicating the need for its further development.

For such an analysis it is first important to decide on the alternatives, the options or scenarios to which S-SRM will be compared. For our analysis here we chose different forms of mitigation as well as unmitigated climate change, which we expect to lead to very bad outcomes and that its burdens will be generally heavier on those worse off in terms of income, education, or social status (Louis and Hess 2008; Schneider et al. 2007). ${ }^{17}$ Second, doing so, it seems relevant what time horizon we take into account and how we design the scenario. Without doubt the framing of the scenario will influence the attractiveness of the different options. For the following example, we will assume the time frame of 2014 until 2100.

We will use the criteria we defined above: human well-being, probability and fairness. We will set the well-being threshold at the protection of people's fundamental interests. For answering the question if this threshold can be fulfilled by an option, we will not be able to describe the expected consequences in detail but rather give a rough estimate of the expected outcomes. The probabilities indicate the chance of attaining a particular outcome/consequence bundle within a chosen option. We will not try to assign numbers to the different options but rather work with probability ranges. Fairness, which plays an important role due to the spatially and temporally heterogeneous distribution of benefits, costs and risks, can range from very fair to very unfair (with a range of intermediate labels such as quite fair, somewhat fair, somewhat unfair, quite unfair). The dimension of fairness takes into account the distribution of benefits and burdens on present and future people (more or less directly) affected by the options, which means that we assume a time frame of roughly 100 years. One important reason for choosing this time frame is that the further we go into

${ }^{17}$ For reasons of simplicity we exclude adaptation-options, even though for some they seem to be the most feasible, due to the low political feasibility of aggressive mitigation and the severe risks and uncertainties of SSRM. 
the future, the less we know about the state of the world, meaning that while the future effects of our policies/choices are always somewhat uncertain once we go too far into the future we simply seem more or less clueless as to how things will look in the future and how strongly present choices will bear on future lives and opportunities.

In the following table we sum up the options that we will compare: aggressive mitigation (AM), moderate mitigation (MM), unmitigated climate change (UCC) ${ }^{18}$ and stratospheric solar radiation management S-SRM. It is important to note that by considering these four options we have already made one important decision, namely, we have decided to include AM even though it is politically not very likely to happen and we included S-SRM despite concerns about its technological and political feasibility. The reason we have done so is simple: while we hold issues of political and technological feasibility to be important, in order to show the potential (and also the limitations) of our consequentialist multidimensional framework we want to consider both AM and S-SRM. In the rest of the paper we will spell out this comparison in more detail and arrive at some preliminary conclusions.

\begin{tabular}{|c|c|c|c|}
\hline & Expected Well-Being (until 2100) & Probability & Fairness \\
\hline $\begin{array}{c}\text { Aggressive } \\
\text { Mitigation } \\
\text { (AM) }\end{array}$ & $\begin{array}{c}\text { negative effects due to still rising } \\
\text { temperatures, but long term basic } \\
\text { interests protection attainable; low } \\
\text { risks for well-being due to climate } \\
\text { change induced impacts }\end{array}$ & $\begin{array}{c}\text { high probability to reach } \\
\text { expected outcome }\end{array}$ & quite fair \\
\hline $\begin{array}{c}\text { Moderate } \\
\text { Mitigation } \\
(\text { MM) }\end{array}$ & $\begin{array}{c}\text { negative effects due to temperature } \\
\text { rise above } 2^{\circ} \text {; increase of severe } \\
\text { weather events; high risks due to } \\
\text { climate change induced impacts }\end{array}$ & $\begin{array}{c}\text { relatively high probability to } \\
\text { reach expected outcome, } \\
\text { however depending on } \\
\text { climate sensitivity as well as } \\
\text { vulnerability and resilience } \\
\text { of environmental and } \\
\text { societal systems }\end{array}$ & quite \\
unfair & \\
\hline $\begin{array}{c}\text { Unmitigated } \\
\text { Climate } \\
\text { Change } \\
\text { (UCC) }\end{array}$ & temperature increase; severe effects \\
globally & $\begin{array}{c}\text { high probability to reach } \\
\text { expected outcome; chance } \\
\text { of unforeseeable } \\
\text { catastrophic outcomes }\end{array}$ & very unfair \\
\hline
\end{tabular}

\footnotetext{
${ }^{18}$ We will not consider UCC in more detail below, but rather take it as a control case for the other options.
} 


\begin{tabular}{|c|c|c|c|}
\hline $\begin{array}{c}\text { Stratospheric } \\
\text { solar radiation } \\
\text { management } \\
\text { (S-SRM) }\end{array}$ & $\begin{array}{c}\text { if it works lessening of harms by } \\
\text { climate change; while climate } \\
\text { changes risks would decrease, side- } \\
\text { effects of deployment could be } \\
\text { severe; }\end{array}$ & $\begin{array}{c}\text { no clear probability to reach } \\
\text { expected outcome, due to } \\
\text { scientific and societal } \\
\text { uncertainties; chance of } \\
\text { unforeseeable catastrophic } \\
\text { outcomes }\end{array}$ & $\begin{array}{c}\text { somewhat } \\
\text { unfair }\end{array}$ \\
\hline
\end{tabular}

table 2

Aggressive mitigation (AM) - defined as a large scale effective mitigation effort starting now and enabling us to stay within the $2^{\circ}$ target until 2100 - scores by far best in terms of wellbeing as well as in terms of fairness. Even though AM would not be able to guarantee the protection of all people's fundamental interests, as it would slow down temperature rise significantly, we expect, if deployed in time, this option to lead to outcomes that would most likely fulfil our well-being threshold to a higher degree than any other option available.

Still, it is not to be forgotten, that AM would also come with costs, especially for those living in industrialized countries. How high these costs would be is open for debate. Nevertheless, it is clear that the burdens and benefits of AM would not be equally divided amongst all people on the planet, as based on the necessary technological transfer and the need of emission reductions and costs will most likely rest on the North, while the benefits will also be on the South. ${ }^{19}$ Still, this seems to be an almost fair distribution, especially if one factors in considerations of historical (in)justice, since the North has caused most greenhouse gas (GHG) emissions and has benefited most from past emissions, while the South is most vulnerable to climate change induced consequences and has (up to now) emitted only a small fraction of the already existing GHG concentrations (Meyer and Roser 2010). Furthermore, AM will also lead to the best outcome from the intergenerational perspective, as people today would take costs to benefit future generations, which will have to bear most of the consequences of global warming (Meyer and Roser 2009). It is also the fairest as it goes

\footnotetext{
${ }^{19}$ One should also consider that mitigation comes with many side-effects that might effect the most vulnerable, like the e-waste problem of the alternative energy sector or justice questions raised in programs for the protection of tropical rain forests. It is important to deal with these problems in a fair and sustainable way.
} 
against the root causes of the problem. In short, AM is pareto-optimal and is therefore the right choice, that is, AM ought to be chosen.

However, when evaluating AM we have to take a particular factor into account: It works best only within a certain time frame. So our evaluation changes, if we were to consider AM starting only in the year 2060, as at this point in time it may already be too late to stop transgressing certain temperature thresholds or climate tipping points by mitigation alone. Therefore, the chances of meeting our threshold of well-being is bound to decrease the longer we wait with our decision.

Moderate mitigation (MM), defined as a slow decline of emissions by 2030, is politically speaking much more likely, but it is expected to only postpone some of the negative outcomes of climate change and / or make them only less bad. Even though mitigation efforts would still have to be substantial, they would most likely fall short to reach the threshold of wellbeing. The probability of reaching the assigned consequence bundle based on our current understanding of climate models and integrated assessment models would depend on climate sensitivity as well as the vulnerability and resilience of environmental and social systems. Therefore the probability that the expected outcome materialises is only relatively high. Even if we assume that future societies would be - due to resilience, technological progress and greater wealth - more adaptable to severe climate change, we expect lower overall levels of well being in comparison with AM, especially from an intergenerational viewpoint. The spatial and temporal difference of impacts of global warming and the 'backloadedness' make the distribution of costs and benefits in the case of MM quite unfair. MM thus fares much worse than AM, since AM scores better across all dimensions, even though in comparison to UCC, MM is more attractive across all dimensions. 
For our evaluation of S-SRM, we use the same time span as for the other options, even though we take it to be unreasonable to even start considering S-SRM before exhausting other options, or reaching a certain threshold, like a climate tipping point or a certain temperature increase (e.g. $2^{\circ}$ ).

In order to non-arbitrarily assign values to S-SRM we have to look more closely at the possible effects of S-SRM. Even if S-SRM works, that is if it lowers the global mean temperature as expected, and by doing so counteracts some severe effects of global warming or even hinders the reach of a climate tipping point, S-SRM is expected to have side-effects and potentially large risks: changes in local temperature, precipitation, and climate patterns such as El Niño and monsoons; effects on regional food and water availability, potentially leading to droughts and famines; ozone depletion; changes in marine and terrestrial biological ecosystems. Furthermore, S-SRM alone will not reverse all adverse effects of rising emissions, like the acidifying effect of carbon dioxide on the oceans. Even if ongoing research may lead to ways to manage some of those risks and side-effects, temperature as well as precipitation differences between regions might increase with duration time, if SSRM is not accompanied by large mitigation efforts. Furthermore, longer periods of S-SRM deployment would create a permanent threat due to a potential termination as the failure to maintain the aerosol counterforcing could result in abrupt and potentially very damaging warming (Ross and Matthews 2009).

Due to the risks involved and the potentially diverse regional climate effects, S-SRM may harm or disadvantage some, while benefiting others (Ricke et al. 2010). The distribution of benefits and costs would not only depend on existing climate conditions but also on population density, economic development and the vulnerability and resilience of ecological, economic and social systems. This could pose particular issues for global fairness, as S-SRM could transfer risks to the poorest countries. Those geographically and economically most 
vulnerable to climate change, often living at the subsistence level, could also be those most likely to be negatively affected by uneven effects of S-SRM and have the lowest capacity to adapt to its consequences, despite being least responsible for global warming (Preston 2012). S-SRM could also increase inequalities between generations if harms and risks are deferred to a later time (Goes et al. 2011; Burns 2011). Whether the deployment of S-SRM would increase existing (or future) inequalities and historical injustice of climate change is, however, an open question, as it may also benefit some of the most vulnerable and poorest countries by reducing climate change-induced risks (Svoboda 2011 et al; Tuana 2013).

Questions about the distribution of effects are even more important considering that S-SRM may fail, and by doing so worsen the harmful consequences of climate change rather than alleviating them. On the one hand, S-SRM could turn out to be of little value, once deployed and associated with severe negative side-effects that are not compensated by the effects of lowering of global mean temperature. If climate change is not just understood as a problem of mean global temperature rise, but more complex by its regional and local impacts, such a (non-catastrophic) failure of S-SRM seems possible (Robock et. al 2008). On the other hand especially non-linear internal feedback between various components of the climate system could result in bifurcations of the system and might therefore lead to abrupt shifts or transitions between states. It is possible that even smaller forcings in certain situations could lead to passing a critical threshold to an unstable condition (Tuana et al. 2012). Especially this mere possibility of unexpected catastrophic consequences that may be far worse than any of the expected ones seem to undermine this option and could jeopardize the ethical acceptability of S-SRM (Davies 2010). ${ }^{20}$

We are aware that this outline of aspects linked to S-SRM opens up more questions then providing answers. The normative evaluation of S-SRM is therefore complex and an

\footnotetext{
${ }^{20}$ For reasons of space we will igonre other potential negative consequences due to the high conflict potential of such techeniques.
} 
open process. However, based on the above-mentioned issues, we will give a preliminary assessment:

When assessing S-SRM one faces one key problem: assigning probabilities towards S-SRM failure or success seems virtually impossible, based on the controversy in the scientific field and the severe uncertainties involved. We also have no idea about the likelihood of catastrophic outcomes, even though the mere chance of such S-SRM catastrophe clearly speaks against deployment. At the same time, we have to consider, that in a scenario of unmitigated climate change, the complexity of the climate system and possible feedback processes might also hold some catastrophic 'climate surprises‘ (Bodansky 2011).

Even though a failure of deployment would very likely increase harms, in the case that S-SRM works and reduces other climate change induced risks we hold it to be possible that our well-being threshold could be satisfied at least to some degree. For the moment this seems realistic even taking into account the known potential side effects. Benefits could also be increased if S-SRM is considered not as a single measure but in combination with other options like increased mitigation efforts or greenhouse gas removal techniques. Doing so one would be able not only to hinder and/or ease out some side effects, but also to decrease the amount and time of S-SRM deployment.

Moreover, S-SRM might actually not be as unfair as moderate mitigation (MM) or unmitigated climate change (UCC), which do nothing or too little to support victims of harms by climate change, especially if it is coupled with compensations for those affected. How fair it is, depends, however, not solely on the success of the option, but also on taking or transferring costs and risks. Even if people at the time of deployment would take at least some risks of S-SRM, the risks of long term implementation and potential termination would be transferred to the future. Therefore, evaluating the fairness of S-SRM it seems justified to conclude that S-SRM will always lead to somewhat unfair outcomes. 
At this point of our analysis, it would be a nice thing, to be able to assign real numbers to all outcomes and to just sum up the scores of AM, MM, UCC and S-SRM in order to reach a conclusion. However, two reasons speak against such a simple aggregation. First, it would contradict our multidimensional account. Second, due to the speculative nature of our assessment and especially the uncertainty regarding the effectiveness of S-SRM, a straight-forward comparison is not possible. What is clear, however, is that AM is better than MM, and MM is better than UCC. Moreover, due to the high probability we attach to AM generating outcomes which meet the thresholds and due to our more sceptical account of SSRM, it seems prudent to choose AM over S-SRM. As our analysis also has shown, though, AM is an option which a) comes with an expiry date, and which b) might not even be on the table due to a lack in political will to engage in AM and to burden its associated short-term costs. Thus, while our obvious recommendation is to engage in AM, the question arises of what to do in case where AM alone is no longer a vital option to hinder considerable harms from climate change and where also additional adaption measures will not be able to hinder most of the climate change induced harms.

To compare MM with S-SRM is much more difficult, precisely because our analysis of S-SRM is based on a range of assumptions built on less than reliable probabilities and guesses. Generally speaking, at this point in time and based on our current knowledge we consider it unreasonable to even start considering S-SRM before exhausting other options, including $\mathrm{MM}$, or reaching a certain threshold, like a climate tipping point or a certain temperature increase (e.g. $\left.2^{\circ}\right)$. Thus, if we had to make a once-and-for-all choice now, our framework speaks in favour of MM over S-SRM. However, since our assessment might change because of increased knowledge regarding S-SRM and its effects (and also because other options might have run their course) or a higher climate sensitivity, we do not think that a strict moratorium on S-SRM research can be defended on the basis of our framework, 
unless one wants to take S-SRM as an option completely off the table. This, however, seems not the advice to give considering UCC.

\section{Conclusion}

Applying our approach outlined in section two to the analysis of climate change policy options shows some strengths as well as some weaknesses of our multi-dimensional consequentialism. Uncertainties remain a great challenge, assigning values to the expected consequences of an option can be difficult and defining thresholds levels can cause controversy, too. One further problem we are well aware of is the possible confusion between our understanding of probability with questions of political and economic feasibility. Even though we focus during our normative evaluation on the probability of a certain consequence bundle once an option is chosen, the question which options are on the table and which are implemented in the end is at least partly determined by feasibility considerations.

Despite all the issues, we think that our consequentialist framework has great potential for dealing with complex decision-making scenarios and that our analysis of table two has shown how our framework can generate guidance for decision-making even when dealing with major uncertainties and limited foreseeability. It clearly indicates that AM is the best option that we have now. Also, we seem to have good reasons to prefer MM over S-SRM deployment in the here and now. However, the circumstances for this assessment might change in the future.

Either way, no matter whether one agrees with our analysis of S-SRM in section three, we hope to have at least shown that employing a satisficing multi-dimensional consequentialist framework in the context of climate change policy options does manage to deal with uncertainties and risk and provides plausible answers. It allows us to carefully assess people's well-being, and an option's probability and fairness, even in complex 
situations; because of that, we take our satisficing multi-dimensional consequentialist framework to be an attractive assessment tool for ethicists and policy-makers alike, helping to reach morally permissible decisions in complex choice situations.

\section{Acknowledgment:}

Research for this paper has benefited from participation in the Research Networking Programme "Rights to a Green Future" that is financed by the European Science Foundation, as well as from financial support by the UFSP Ethik of the University of Zurich. Work was also supported by the CEMICS (Contextualizing Climate Engineering and Mitigation: Illusion, Complement or Substitute) project of Priority Programme (SPP 1689) of the German Research Foundation. Earlier versions of the paper were presented at the ECPR Joint Sessions in Mainz, as well as the Institute for Advanced Sustainability Studies (IASS) in Potsdam. We would like to thank the audiences at both occasions for helpful comments and criticisms. In particular we would like to thank Gregor Betz, Tobi Svoboda, Martin Peterson, and Simon Hailwood, as well as two anonymous referees for Environmental Values for their insightful suggestions on how to improve the text.

\section{References}

Bodansky, D. 2011. 'Governing climate engineering: scenarios for analysis discussion', Paper 2011-47, Harvard Project on Climate Agreements.

Bradley, B. 2006. 'Against satisficing consequentialism', Utilitas, 18: 97-108.

Burns, W. 2011. 'Climate geoengineering: solar radiation management and its implications for intergenerational equity'. Stanford Journal of Law, Science \& Policy, 4, 39-55.

Darwall, S. (ed.) 2003. Consequentialism. Oxford: Blackwell.

Davies, G. 2010. 'Geoengineering: a critique'. Climate Law, 1: 429-441.

Goes, M., Tuana, N. and Keller K. 2011. 'The economics (or lack thereof) of aerosol geoengineering'. Climatic Change, 109: 719-744.

Hamilton, C. 2011. 'The ethical foundations of climate engineering'. Unpublished Manuscript.

Jackson, F. 1991. 'Decision-theoretic consequentialism and the nearest and dearest objection'. Ethics, 101: 461-482. 
Lenman, J. 2000. 'Consequentialism and cluelessness'. Philosophy \& Public Affairs, 29: 34270.

Louis, M.E.S. and Hess, J.J. 2008. 'Climate change impacts on and implications for global health'. American Journal of Preventive Medicine, 35: 527-538.

Matthews, D.H., and Caldeira, K. 2007. 'Transient climate-carbon simulations of planetary geoengineering'. Proceedings of the National Academy of Sciences, 104: 9949-9954.

Meyer, L.H. and Roser, D. 2009. 'Enough for the future'. A. Gosseries and L.H. Meyer, (eds.), Intergenerational Justice, pp. 219-248. Oxford: Oxford University Press. and Roser D. 2010. 'Climate justice and historical emissions'. L.H. Meyer and M. Matravers, (eds.), Justice, Equality and Democracy, Special Isssue of Critical Review of International Social and Political Philosophy, 13: 229-253.

Mulgan, T. 1993. 'Slote’s satisfying consequentialism'. Ratio, 6: 121-134.

Mulgan, T. 2001. 'How satisficers get away with murder'. International Journal of Philosophical Studies, 9: 41-46.

Norcross, A. 1990. 'Consequentialism and the unforeseeable future'. Analysis, 50: 253-256.

Oberdiek, J. 2012. 'The moral significance of risking'. Legal Theory, 18: 339-356.

Peterson, M. 2012. 'Multi-dimensional consequentialism'. Ratio, 25: 177-194. 2013. The Dimensions of Consequentialism: Ethics, Equality and Risk. Cambridge: Cambridge University Press.

Pettit, P. 1984. 'Satisficing consequentialism'. Proceedings of the Aristotelian Society, Supplementary Volumes 58: 165-176.

Preston, Ch. J. 2012. 'Solar radiation management and vulernable populations. The moral deficit and its prospect'. In: Preston, Ch. J. (ed.), Engineering the climate: the ethics of solar ration management, pp. 77-93. Plymouth: Lexington Books. 
2013. 'Ethics and geoengineering: reviewing the moral issues raised by solar

radiation management and carbon dioxide removal', Wiley Interdisciplinary Reviews:

Climate Change, 4: 23-37.

Ricke, K. L., et al. 2010. 'Regional climate response to solar-radiation management', Nature Geoscience, 3: 537-41.

Robock, A. Oman, L. and Stenchikov, G.L. 2008. 'Regional climate responses to geoengineering with tropical $\mathrm{SO}_{2}$ injections'. Journal of Geophysical ResearchAtmospheres, 113, No. D16.

Rogers, J. 2010. 'In defense of a version of satisficing consequentialism'. Utilitas, 22: 198221.

Ross, A. and Damon Matthews, H. 2009. 'Climate engineering and the risk of rapid climate change', Environmental Research Letters, 4: 45-103.

Schneider, S.H. et al. 2007. 'Assessing key vulnerabilities and the risk from climate change'. In M.L. Parry et al.(eds.), Climate Change 2007: Impacts, Adaptation and Vulnerability. Contribution of Working Group II to the Fourth Assessment Report of the Intergovernmental Panel on Climate Change, pp. 779-810. Cambridge: Cambridge University Press.

Schäfer, S. et al. 2015. Removing Greenhouse Gases from the Atmosphere and Reflecting Sunlight away from Earth. An Assessment from a European Perspective. Final report of the FP7 CSA project EuTRACE (forthcoming).

Schuppert, F. 2013. 'Distinguishing basic needs and fundamental interests'. Critical Review of International Social and Political Philosophy 16: 24-44.

Sinnott-Armstrong, W. 2012. 'Consequentialism'. Stanford Encyclopedia of Philosophy, available at plato.stanford.edu/entries/consequentialism/ < accessed 15.01.2013> 
Slote, M. 1984. 'Satisficing consequentialism'. Proceedings of the Aristotelian Society, Supplementary Volumes 58: 139-63.

Smart, J.J.C. and B. Williams 1973. Utilitarianism: For and Against. Cambridge: Cambridge University Press.

Smart, J.J.C. 1973. 'An outline of a system of utilitarian ethics'. In: J.J.C. Smart and B. Williams (eds.), Utilitarianism: For and Against, pp. 3-74. Cambridge: Cambridge University Press.

Svoboda, T., Keller, K. Goes, M. and Tuana, N. 2011. 'Sulfate aerosol geoengineering: The question of justice'. Public Affairs Quarterly, 25: 157-179.

Swart R. and Marinova, N. 2010. 'Policy options in a worst case climate change world. Mitig Adapt Strateg Glob Change 15: 531-549.

Thomson, J.J. 1986. Rights, Restitution, and Risk. Cambridge MA: Harvard University Press.

Tuana, N. et al. 2012. 'Towards integrated ethical and scientific analysis of geoengineering: A research agenda', Ethics, Policy \& Environment, 15: 136-157.

Tuana, N. 2013. 'The ethical dimensions of geoengineering: Solar radiation management through sulphate particle injection', Geoengineering Our Climate Working Paper and Opinion Article Series, accessed 4.3.2014 